\title{
Physics at the Crossroads
}

\begin{abstract}
Excerpts from the presentation made by Norbert Kroo at the 13th General Conference of the EPS Condensed Matter Division in Regensburg on 1 April 1993 just a few hours after assuming office as the President of EPS.
\end{abstract}

I consider it symbolic that now, when science, and physics, in particular are in a certain sense at a crossroads, we convene here, in Regensburg at a crossing-point of north and south, east and west. Our responsibility in Europe is large since many of the basic ideas of modern physics were born here in Europe. For the last two generations science has been dominated by physicists. The objective basis for this is the rôle of physics in major discoveries. There is, however, a subjective reason as well. Since money was not short, and the prestige of physicists was high, many of the best brains decided to work in the field.

Due mainly to economic reasons, the financial support for science is decreasing along with the social prestige. This tendency can be seen perhaps most explicitly in physics. The "internal" reasons are that while physics is the basis for almost all natural sciences, it did not take care of its internal proportions so too many gigantic projects were started. "External" reasons include the general feeling in society that new discoveries pollute, that physics is dangerous and technology inhuman. It is also not clear who is, economically speaking, more valued - the engineer or the physicist. Finally, the proportion of research funds which should be spent on the environment is not defined. I am, however, optimistic concerning the future of physics in Europe as physics has proved several times its adaptive capabilities.

\section{Shifting Emphasis}

I believe physics is going to remain the basis of all fundamental sciences, and that these sciences will remain, or become more definitely, the basis of technological development. Relations between fundamental science and technological change must become closer: the capabilities of the innovator will have to include knowledge of the basic sciences; innovation will become more science-based. These developments come at the price of increasing research costs - a trend that has been evident for many years. So even the largest and wealthiest countries face the need to make hard choices in the scientific projects and fields they finance.

Norbert Kroo is Director, Institute of SolidState Physics, Hungarian Academy of Sciences, Budapest.

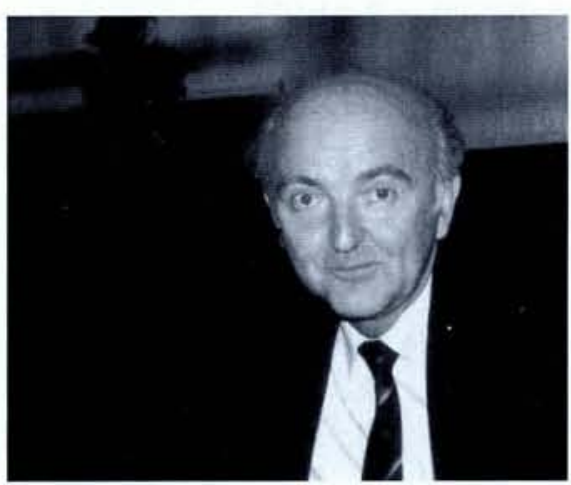

Technical innovation largely consists of marginal changes, not basic research which is anyway increasingly becoming more widely available in our era of telecommunications and high-speed transport. So small countries increasingly question the rôle of basic research and the extent to which it should be financed domestically. To counterbalance this tendency we should strengthen those aspects of physics which are clearly acknowledged by society. We have to understand the trends of our constituents and think in terms of the needs of people paying the bill.

Perhaps more than anything else, flexibility - especially intellectual flexibility - must be fostered as success will require people who can learn new fields, stay in touch with developments, and maintain good contacts with colleagues throughout the world. Physics education leading to basic understanding is going to play a larger rôle in this training process. This is because basic scientific knowledge, particularly in physics, does not become obsolete as knowledge does at an ever increasing rate in many other fields. Moreover, much of physics brings convergence into otherwise diverging branches of science, and is thus needed by an increasing number people in other professions.

The pool of scientific and technical knowledge cannot be tapped effectively except by personal interventions by capable scientists; this is best done through personal contacts. Strong interaction with the European scientific community is therefore vital, and organizations such as EPS can play an increasingly important rôle.

\section{EPS in a Changing World}

The more I am involved with the Society the more I admire our founders. They built up a society with a good balance between large and small national societies, between individuals and societies without forgetting that the Divisions are the basis of our professional activity. For us in eastern and central Europe, EPS has been one of the most important links to the western physics community. EPS was in his respect far ahead of any other organization in Europe.

This Europe has, however, fortunately changed and we are facing new challenges. We have to increase therefore the visibility of EPS all around Europe, both within and outside the physics community by doing things better, and by starting up new activities which cannot be done on a national scale, by integrating national cultures into a large European venture.

In order to prepare for this task, the Council of EPS accepted last week the first steps of a restructuring process. The final goal is clear: a real European society with a large number of individual members. The conditions for this step are, however, not yet ripe and the goal may take many years to reach.

To start the process, a new membership category was accepted (subject to approval by the membership) namely that of a so-cal- led Full Member Society. If a national society decides to go along these lines, its members become automatically members of EPS with many of the rights of the present individual members.

Some other ideas are also starting to crystallise. The representation of the Divisions in Council and in the Executive Committee will be increased; connection to the industrial world, to physics teachers, to young physicists, and to other physics-related societies will be improved, and more attention will be paid to international organizations, especially the European ones such as the European Community and the European Science Foundation. Our expertise is offered to funding organizations for the study of possible new European projects, for organizing schools and conferences, and, in particular, for exploiting our experience in east-west relations. Indeed, our East-West Coordination Committee is very active in helping colleagues and institutions in central and eastern Europe by organizing conferences on the management and financing of research, and by supplying journals, books, and even equipment.

New actions are in preparation: the student mobility programme looks very promising. It will enable young physicists to interact with a global scientific community in the early stages of their scientific careers.

\section{A Place to Act}

EPS can be the place which brings together on the European scale the cultures of research and applications, of scientists and the users of science, of academia and industry. This way of thinking should also start in the early phase of an individual's career, i.e., as a student. Without going into details, one conclusion is, however, clear: EPS is, and will become even more so, a good place to work for European physics - for its future as part of a hopefully prosperous, unified Europe.

The many difficulties our physical societies are facing do not make this a smooth road: they might perhaps even swell up to a general crisis level. The word "crisis" is written in Chinese with two symbols with the meanings "danger" and "opportunity"; we are living in dangerous times with many opportunities in our hands. If we want to explore opportunities, the first thing we have to do is to spread out the existing knowledge by high-level education and to make use of it in a human way.

\section{AMENDMENT TO THE CONSTITUTION President-Elect}

The 1993 Council of EPS accepted a proposal by the Executive Committee that Article 19 of the Constitution be amended whereby item $2 \mathrm{~b}$ ) becomes $2 \mathrm{c}$ ) and the new $2 \mathrm{~b}$ ) will read: "The candidate for Presidency shall be the President-Elect who is elected one year before the election to President takes place. During this year the President-Elect will act as the VicePresident."

According to Article 18, Ordinary Members, Fellows and the Executive Committee have 40 days from publication of this announcement to request that Council's decision be submitted to a ballot of the General Meeting, voting by mail. 